\title{
Fecal indicator bacteria along multiple environmental exposure pathways (water, food, and soil) and intestinal parasites among children in the rural northwest Ethiopia
}

Zemichael Gizaw ${ }^{1,2,3^{*}}$, Alemayehu Worku Yalew ${ }^{4}$, Bikes Destaw Bitew ${ }^{1}$, Jiyoung Lee ${ }^{5,6}$ and Michael Bisesi ${ }^{5}$

\begin{abstract}
Background: Children in low-resource settings are exposed to multiple risk factors for enteropathogens. However, the probability of exposures may be different across exposure pathways. Accordingly, this study was conducted to assess environmental exposures of children to intestinal parasites in the east Dembiya district of Ethiopia.

Methods: A cross-sectional study was conducted for 372 households with children aged 24-59 months. The potential for external exposure of children to intestinal parasites was assessed by determining the presence of fecal indicator organism (Escherichia coli (E. coli)) in drinking water at point of use, ready-to-eat foods, and courtyard soil from children's outdoor play areas. For internal exposure assessment, ova of parasites in stool samples was detected using wet mount and Kato-Katz techniques to estimate exposure to intestinal parasites. The external and internal exposure assessments were also complemented using questionnaire and spot-check observations to assess behaviors that result in high risk of exposure. Individual and community-level predictors of intestinal parasites were identified using a multilevel logistic regression model. Statistically significant variables were identified on the basis of adjusted odds ratio (AOR) with 95\% confidence interval (Cl) and $p$-value $<0.05$.

Results: Ova of one or more intestinal parasites was detected among 178 (47.8\%) (95\% Cl 42.8, 52.6\%) of the children. The most common intestinal parasites were A. lumbricoides (20.7\%) and S. mansoni (19.1\%). Furthermore, E. coli was detected in $69.1 \%$ of drinking water samples at point of use, $67.5 \%$ of ready-to-eat food samples, and $83.1 \%$ of courtyard soil samples from children's outdoor play areas. Exposure of children to intestinal parasites among children in the studied region was associated with poor hand hygiene of mothers (AOR 1.98,95\% Cl $(1.07,3.66)$, poor hand hygiene of children (AOR 3.20, 95\% Cl $(1.77,5.77)$, mouthing of soil contaminated materials (AOR 2.31, 95\% Cl (1.26, 4.24), open defecation practices (AOR 2.22, 95\% Cl (1.20, 4.10), limited access to water (AOR 2.38, 95\% Cl (1.13, 5.01), water contamination (AOR 2.51,95\% Cl $(1.31,4.80)$, food contamination (AOR 3.21, 95\% Cl $(1.69,6.09)$, and soil contamination (AOR 2.56, 95\% Cl $(1.34,4.90)$.
\end{abstract}

Conclusion: An extensive E. coli contamination of water, foods, and courtyard soil was found in the studied region and the potential sources of contamination were open defecation practices, unhygienic disposal of wastes, poor

\footnotetext{
*Correspondence: zemichael12@gmail.com

1 Department of Environmental and Occupational Health and Safety,

Institute of Public Health, College of Medicine and Health Sciences,

University of Gondar, Gondar, Ethiopia

Full list of author information is available at the end of the article
} 
animal husbandry and keeping practices, and poor water and food safety measures at household level. Moreover, fecal contamination of water, foods, and soil linked to exposure of children to intestinal parasites in the studied region. Thus, it is critical to implement individual-level interventions (such as latrine utilization, hand hygiene promotion, food safety, home-based water treatment, and containment of domestic animals), plus community-level interventions (such as protecting water sources from contamination, source-based water treatment, and community-driven sanitation).

Keywords: E. coli contamination of water, E. coli contamination of ready-to-eat foods, E. coli contamination of courtyard soil, Hand hygiene, Mouthing of soil contaminated materials, Sanitation, East Dembiya district

\section{Background}

Enteric infections are the leading causes of death in children, especially in developing countries. Enteric infections are the cause for approximately 589,000 deaths among children under the age of 5-years in 2017 all over the world [1]. Intestinal parasitic infections are among the most common enteric infections worldwide. More than 1.5 billion people were infected with soil-transmitted helminth infections (STHs) in 2020 [2] and latest estimates indicate that more than 880 million children are in need of treatment for these parasites [3]. Population at risk in African is estimated at 350 million, with the highest infection rate per population occurring in sub-Saharan Africa [3]. About 79 million people are living in STHs endemic areas in Ethiopia, out of which 9.1 million are pre-school-aged children [4].

The burden of enteric infections is high among children compared to the adult population [5]. Children, especially in low-resource settings experience to a variety of enteropathogen risk factors from various sources and exposure pathways (e.g., water, soil, and food). Enteropathogens spread from feces to new hosts via complicated, environmentally mediated pathways. Fecal pathogens can spread into fields and ambient waters in areas with poor sanitation. These are then transported into drinking water and food by fomites (e.g., containers) and vectors (e.g., hands and flies) and ingested by young children through mouth contact with contaminated hands and objects [6].

In areas where children have multiple environmental exposures to enteropathogens, identifying the sources of exposure is critical for planning and implementing effective strategies to reduce transmission of enteric infection [7]. There are numerous approaches for measuring human exposure to enteropathogens along the environmental exposure pathways, ranging from those that measure environmental concentrations of contaminants to predict exposures before the contaminant reaches the human boundary (external exposure assessment) to those that estimate a dose after the contaminant has been taken up into the body (internal exposure assessment) and measurement of host interaction with the environment, as documented by Goddard et al. [7].

The detection of indicators of fecal contamination in environmental samples is a common approach for external exposure assessment. The most common indicator organism of fecal contamination is $E$. coli, which is more specific to warm blooded animals and can be used to track source of environmental contamination [8]. However, measuring environmental exposures using indicator organisms of fecal contamination does not precisely estimate how much enteropathogen crossed the human body envelope [7]. Internal exposure assessments using biological specimens, on the other hand, estimate enteropathogen exposure after it has passed through the human body. Internal exposure assessment, however, provides limited information for tracking the source of environmental contamination [9]. Exposure to enteropathogens is not only conditional on pathogen presence in the environment, but also on host interaction with that environment. Capturing behaviors that result in high risk of exposure using survey or observational data complements exposure assessments and can enable the targeting of environmental media and locations where the study population is predominantly exposed [7]. The SaniPath exposure assessment tool is an important tool to collect environmental samples and information on behaviors that result high risk of exposure. This approach follows the framework for quantitative microbial risk assessment, with an emphasis on hazard identification, exposure assessment, risk characterization, and risk management $[10,11]$.

Even though, numerous approaches for measuring human exposure along the environmental exposure pathway continuum, are available, evidence is limited in Ethiopia that document the exposure pathways of children to intestinal parasites. Moreover, the probability of exposures may be different across exposure pathways and little is known about which conditions pose the greatest risk for pathogen exposure. Accordingly, this study was conducted to assess environmental 
exposures of children to intestinal parasites in the east Dembiya district of Ethiopia.

\section{Methods}

\section{Study settings}

This study was conducted in the rural settings of the east Dembiya district of Ethiopia from 01 May to 18 June 2021, which was a dry season. The east Dembiya is one of the districts in central Gondar zone, the Amhara national regional state, Ethiopia. As of July 2020, the district had a total of 192,020 rural and 18,741 urban residents [12], of these, 39,927 (12.22\%) were children under age 5-years [13]. In the district, coverage of clean water and latrine were $26.6 \%$ and $55 \%$, respectively. Moreover, intestinal parasitic infections were the top four prevalent diseases, which accounted 5161 (9.97\%) [14].

\section{Study design}

A community-based cross-sectional study design with structured observation and laboratory investigations was employed to measure environmental exposures of children to intestinal parasites. We used the Goddard et al. [7] and the SaniPath exposure assessment [11] approaches to assess exposure of children to intestinal parasites. These approaches are discussed in more detail in the background section.

\section{Sample size determination}

Sample size was calculated using double population proportion formula with the following assumptions: prevalence of STH among preschool age children who had access to drinking water from protected spring in Chuahit, northwest Ethiopia $=53.3 \%$ and prevalence among children who had access to drinking water from well water $=31.6 \%$ [15], $Z_{\alpha / 2}$ at type 1 error of $5 \%=1.96, Z_{\beta}$ at $80 \%$ power $=0.842$, and allocation ratio $=1: 1$. Therefore, the sample size $n=81$. After considering a design effect of 2 and $15 \%$ non-response rate, the final sample size in each group was found to be 186 , leading to a total of 372 study subjects.

\section{Sampling procedures}

All households in the rural kebeles (the lowest administrative unit in Ethiopia) in the district were considered for sampling. First, we chose six rural kebeles at random out of 28 kebeles using a simple random sampling technique. We allocated equal number of mothers or care givers-child pairs to each kebele. Finally, 372 households with children aged 24-59 months were included in the study using a systematic random sampling technique. Data collectors began collecting data in households located on the right side of local administrators' offices. Assuming that each rural kebele has an average of 200 households [16, 17], a sampling interval $(K=3)$ was calculated dividing 200 by the kebele's predetermined sample size (i.e., 62). Following that, a number between one and the sampling interval was chosen at random using the lottery method. After the first random start, every third household with children aged 24-59 months was sampled until the desired sample size for each kebele was reached. The younger one was included in the study for households having two children aged 24-59 months.

\section{Environmental sample collection and transportation}

Drinking water samples at point of use, food samples from ready-to-eat foods, and courtyard soil samples from children's outdoor play areas were collected aseptically for external exposure assessment. Water, foods, and soil were considered to assess external exposure because these three environmental compartments are the principal transmission pathways along the enteric pathogens exposure pathway continuum $[18,19]$. To collect stored water, field workers asked mothers or caregivers to provide a glass of water from their primary drinking water storage container, as if they were giving it to their children, and pour $100 \mathrm{ml}$ into a sterilized sampling bottle [19]. To collect soil samples, the respondents were asked to identify the outdoor area where the youngest child aged 24-59 months had most recently spent time and field workers then scraped the top layer of soil into a sampling bag with a sterile scoop to collect approximately $50 \mathrm{~g}$ of soil [19]. To sample ready-to-eat foods, field workers asked mothers or care givers to provide approximately $2 \mathrm{~g}$ of food in the same manner they feed their children and we scooped the whole portion to fill a sterile plastic bag (Minigrip GreenLine Biodegradable Reclosable Zipper Bag) using a sterile spoon [19].

All samples were preserved on ice and transported to the laboratory to be processed on the same day, typically within $6 \mathrm{~h}$ of collection. Upon arrival at the laboratory, samples were kept on ice until they were processed.

\section{Stool sample collection}

Field workers first explained the purpose of collecting stool from children to mothers or caregivers, and then asked them to tell their children to defecate. To avoid urine contamination of the stool, field workers or mothers or care givers instructed the child to urinate first without pooping. Field workers then handed out paper to mothers or caregivers, instructing them to have their child defecate on it to avoid stool contamination with soil or dirt. Field workers used wooden stick to transfer approximately $50 \mathrm{~g}$ of the last part of the stool, the softest 
part, into the collection container after the child defecated on the paper. The field workers then immediately delivered the sample to the stool examination team, who stationed at the center of the village where stool samples were collected in order to facilitate fresh stool analysis.

\section{Household data collection}

To measure host interactions with the environment, interviewers-administered questionnaire and spot-check observations were used to collect information on behaviors that result in high risk of exposure. Questionnaire and observation checklists were prepared based on a review of relevant literature. The tool was first prepared in English language and translated to the local Amharic language by two native Amharic speakers fluent in English, and back-translated into English by two independent English language experts fluent in Amharic to check consistency. After translation, the tool was tested for validity and internal consistency (CVR: 0.95, I-CVI: 0.97, S-CVI/ UA: 0.95, modified kappa: 0.97, and Cronbach's alpha for internal consistency: 0.85). The tool was organized in to eight parts: (i) socio-demographic information, (ii) access to health and sanitation information, (iii) personal hygiene, (iv) waste management practices, (v) drinking water quality and safety measures, (vi) food hygiene and safety measures,( vii) housing conditions, and (viii) childhood diarrheal disease. Field workers observed child behaviors that would result in hand or mouth contact with environmental fomites (mouthing of soil or soil contaminated materials, such as objects or foods on the ground, eating dirt, mouthing hands, etc.) for $30 \mathrm{~min}$ spot observation. Field workers also observed the presence of human or animal excreta in the living environment. Furthermore, handwashing data were gathered by assessing mothers' or caregivers' usual handwashing behavior using self-reports. Field data collectors also looked at the hands of mothers or care givers, including children, to see the general cleanliness and conditions of fingernails. In addition, field data collectors asked mothers or care givers to demonstrate how they wash their hands on a regular basis, which they evaluated using checklists for effective handwashing.

\section{Detection of $E$. coli in water, food and soil samples}

$1 \mathrm{~g}$ of food and soil samples were homogenized with a sterile peptone-buffered water (PBW, 0.1\%) $(10 \mathrm{ml}$ for food and $20 \mathrm{ml}$ for soil) using a sterile blending bag and a laboratory-scale processor for $1 \mathrm{~min}$ at the specified mixing speed. Serial dilutions were done using sterile distilled water by tenfold dilution. $10 \mathrm{ml}$ of solution from $10^{-4}$ to $10^{-3}$ dilutions were taken. The water samples were not diluted before being analyzed. The entire water sample, soil, and food solutions were separately filtered through a $47-\mathrm{mm}$ diameter, $0.45-\mu \mathrm{m}$ pore-sized sterile filter membrane (Millipore, Burlington, MA, USA) and cultured on membrane lauryl sulphate broth pouring into an absorbent pad (Oxoid Limited, Basingstoke, UK). The prepared samples were incubated for $24 \mathrm{~h}$ at $44.5{ }^{\circ} \mathrm{C}$ before counting the number of colony forming units (CFU) according to the standard procedures outlined in the WHO guideline [20]. The filtration apparatus was washed with distilled water and flamed between analyses of consecutive samples and sterilized at intervals. The colony number was counted and the results were expressed as CFU per $100 \mathrm{ml}$ of water or $1 \mathrm{~g}$ of soil and food samples by taking into consideration of dilution factors. One field blank per sample collectors per week, plus one laboratory blank per laboratory assistants per day were processed for quality control.

Based on the number of colonies of E. coli per $100 \mathrm{ml}$ of water sample, the quality of drinking water was taken as conformity (if $0 \mathrm{CFU}$ of $E$. coli per $100 \mathrm{ml}$ ), low risk (1-10 CFU/100 ml), intermediate risk (10-100 $\mathrm{CU} / 100 \mathrm{ml}$ ), high risk (100-1000 CFU/100 ml), and very high risk (41,000 CFU/100 ml were found) [21]. Furthermore, the quality of ready-to-eat foods was considered "satisfactory" if the mean E. coli counts recovered in $1 \mathrm{~g}$ of food samples was less than $20 \mathrm{CFU}$, "borderline" if the mean $E$. coli counts recovered was between 20 and $100 \mathrm{CFU}$, and "unsatisfactory" if the mean $E$. coli counts recovered was greater than $100 \mathrm{CFU}$ [22].

\section{Detection of ova of parasites in stool samples}

Ova of intestinal parasites in stool samples were detected using direct stool examination (wet mount) and KatoKatz techniques. Stool specimens were diluted with saline as necessary for direct examination. $0.05 \mathrm{~g}$ of stool specimen was placed, mixed with a drop of saline, and covered with a cover slide. Finally, the specimen was examined under the microscope at low ( $\times 10$ objective) and high $(\times 40$ objective) magnification powers for the identification of intestinal parasites [23]. A small amount of feces (approximately $2 \mathrm{~g}$ ) was placed on a scrap piece of paper for the Kato-Katz. Using applicator stick, the stool was pressed against the top of the fecal specimen's screen. The template was placed on a clean microscopic slide and filled with the sieved fecal specimen after the upper surface of the screen was scraped to sieve the fecal specimen. The template was then carefully removed, leaving the entire fecal specimen on the slide. The fecal specimen that remained was covered with a glycerolsoaked cellophane strip and examined under $a \times 10$ objective microscope [23].

The intensity of intestinal parasites was determined based on the number of parasitic eggs per gram (EPG) of the stool sample. The intensity of intestinal parasites was 
grouped into light (Ascaris lumbricoides, 1-4999 EPG; Hookworm, 1-1999 EPG; Schistosoma mansoni, 1-99 EPG; Hymenolepis nana, 1-1999 EPG; Trichuris trichiura, 1-999 EPG); moderate (Ascaris lumbricoides, 500049, 999 EPG; Hookworm, 2000-3999 EPG; Schistosoma mansoni, 100-399 EPG; Hymenolepis nana, 2000-9999 EPG; Trichuris trichiura, 1000-9999 EPG); and heavy (Ascaris lumbricoides, $\geq 50,000$ epg; Hookworm, $\geq 4000$ EPG; Schistosoma mansoni, $\geq 400$ EPG; Hymenolepis nana and Trichuris trichiura, $\geq 10,000$ EPG [24, 25].

\section{Statistical analysis}

Stata version 14 (Stata Corp, College Station, TX, USA) was used to analyze data. Multilevel bivariate and multivariable analysis using cluster-level random effects binary logistic regression models were used to assess the independent effects of community factors and moderating effects on the association between individual variables and exposure to intestinal parasites. A two-level binary logistic regression model was applied (i.e., 372 households with children under the age of five-years (level 1) nested within 17 clusters with common water sources (level 2). Both random-intercept and random coefficient logistic models were fitted to estimate associations between the individual and community variables to intestinal parasites using xtmelogit Stata command. The null model is fitted without the explanatory variable. The random-intercept logistic models were fitted to assess the influence of unobserved community level characteristics on the prevalence of intestinal parasites allowing the likelihood of exposure to vary randomly across communities assuming the effects of individual characteristics are the same in each community. While the random coefficient model was fitted for drinking water quality at point of use, allowing to vary across communities. Finally, both individual and community variables were adjusted and a cross-level interaction between water sources and water quality at point of use to see evidence of effect modification of the association between water sources and water quality at individual households. We followed a simplified procedures stated by Sommet N and Morselli D [26]. Statistically significant variables were identified on the basis of adjusted odds ratio (AOR) with 95\% confidence interval $(\mathrm{CI})$ and $p$-value $<0.05$. Intra-cluster correlation (ICC), was calculated to measure the variation between clusters. The fitness of models were assessed using the global Wald's statistics, the likelihood ratio test of the cluster-level random effects, and Akaike information criterion (AIC).

\section{Results}

Sociodemographic characteristics of mothers or care givers and children

A total of 372 households with children under the age of five-years participated in this study, with a $100 \%$ response rate. The youngest and oldest mothers or care givers ranged from 20 to 45 years, with a mean $( \pm S D)$ age of $31.7( \pm 6.4)$ years. One hundred twenty-eight $(34.4 \%)$ of the mothers or care givers were between the ages of 26 and 30 years. The vast majority, 336 (90.3\%) of the mothers or care givers were married and 164 (44.4\%) of the mothers or care givers can't read and write. The households included in the current study ranged in size from 2 to 8 members, with 133 (35.8\%) having more than 5 family members. One hundred and ninety-two (51.6\%) of the children in this study were male. Children ranged in age from 24 to 59 months, with a mean $( \pm S D)$ age of 42 $( \pm 12.5)$ months. One hundred fifty-eight $(42.5 \%)$ of the children were aged between 48 and 59 months (Table 1).

Table 1 Sociodemographic characteristics of mothers or care givers and children in the rural settings of the east Dembiya district, northwest Ethiopia, May-June 2021, ( $n=372)$

\begin{tabular}{|c|c|c|}
\hline Sociodemographic variables & Frequency & Percent \\
\hline \multicolumn{3}{|c|}{ Age of mothers or care givers in years } \\
\hline $20-25$ & 74 & 19.9 \\
\hline $26-30$ & 128 & 34.4 \\
\hline $31-35$ & 64 & 17.2 \\
\hline $36-40$ & 82 & 22.0 \\
\hline $41-45$ & 24 & 6.5 \\
\hline \multicolumn{3}{|c|}{ Marital status of mothers or care givers } \\
\hline Married & 336 & 90.3 \\
\hline Divorced & 25 & 6.7 \\
\hline Widowed & 11 & 3.0 \\
\hline \multicolumn{3}{|c|}{ Education status of mothers or care givers } \\
\hline Can't read and write & 165 & 44.4 \\
\hline Can read and write & 34 & 9.1 \\
\hline Primary education & 57 & 15.3 \\
\hline Secondary education & 68 & 18.3 \\
\hline Certificate/ diploma & 48 & 12.9 \\
\hline \multicolumn{3}{|l|}{ Family size } \\
\hline$\leq 5$ & 239 & 64.2 \\
\hline$>5$ & 133 & 35.8 \\
\hline \multicolumn{3}{|l|}{ Sex of child } \\
\hline Male & 192 & 51.6 \\
\hline Female & 180 & 48.4 \\
\hline \multicolumn{3}{|l|}{ Age of children in months } \\
\hline $24-36$ & 92 & 24.7 \\
\hline $37-48$ & 122 & 32.8 \\
\hline $49-59$ & 158 & 42.5 \\
\hline
\end{tabular}




\section{Hand hygiene of mothers or care givers and children} In the current study, 362 (97.3\%) of the mothers or care givers reported that they always washed hands before feeding, 296 (79.6\%) washed before preparing foods, and $276(74.2 \%)$ washed after defecating their children. One hundred fifty-seven (42.2\%) and 130 (34.9\%) of the mothers or care givers reported they washed hands with water alone and with soap, respectively. Furthermore, $122(32.8 \%)$ and $200(53.8 \%)$ of mothers or care givers reported that they always washed hands of children after they played and before they ate, respectively. Results from the observation revealed that only 65 (17.5\%) of the mothers or care givers thoroughly rubbed all parts of their hands for at least $20 \mathrm{~s}$, and 44 (11.8\%) of the mothers or care givers wiped their hands on their cloth to dry. Furthermore, $253(68.0 \%)$ of the mothers or care givers and $215(57.8 \%)$ of the children did not keep their fingernails short and clean. Two hundred and forty-seven (66.4\%) of the children mouthed soil contaminated materials (Table 2).

\section{Waste management practices}

This study revealed that 130 (34.9\%) of the rural households used traditional pit latrine $242(65.1 \%)$ of the households defecated in the open field. Three hundred and nineteen $(85.8 \%)$ of the rural households disposed

Table 2 Hand hygiene practice of mothers or care givers and children in the rural settings of the east Dembiya district, northwest Ethiopia, May-June 2021, $(n=372)$

\begin{tabular}{|c|c|c|}
\hline Hand hygiene practice & Frequency & Percent \\
\hline \multicolumn{3}{|l|}{ Mothers or care givers always washed hands } \\
\hline After visiting toilet & 266 & 71.5 \\
\hline After defecating a child & 276 & 74.2 \\
\hline Before feeding a child & 362 & 97.3 \\
\hline Before preparing foods & 296 & 79.6 \\
\hline After handling rubbish & 326 & 87.6 \\
\hline After touching animals & 304 & 81.7 \\
\hline \multicolumn{3}{|l|}{ What mothers or care givers usually used to wash hands } \\
\hline Water alone & 157 & 42.2 \\
\hline Soap & 130 & 34.9 \\
\hline Leaf & 17 & 4.6 \\
\hline Ash & 54 & 14.5 \\
\hline \multicolumn{3}{|c|}{ How mothers or care givers washed hands during the observation } \\
\hline Used soap & 118 & 31.7 \\
\hline Used ash & 21 & 5.6 \\
\hline Thoroughly rubbed all parts of the hand for at least $20 \mathrm{~s}$ & 65 & 17.5 \\
\hline Wiped hands on their cloth after washing & 44 & 11.8 \\
\hline Dried in the air after washing & 328 & 88.2 \\
\hline \multicolumn{3}{|c|}{ Mothers or care givers always washed hands of children after playing } \\
\hline Yes & 122 & 32.8 \\
\hline No & 250 & 67.2 \\
\hline \multicolumn{3}{|c|}{ Mothers or care givers always washed hands of children before eating } \\
\hline Yes & 200 & 53.8 \\
\hline No & 172 & 46.2 \\
\hline \multicolumn{3}{|l|}{ Mothers or care givers kept fingernails short and clean } \\
\hline Yes & 119 & 32.0 \\
\hline No & 253 & 68.0 \\
\hline \multicolumn{3}{|l|}{ Children kept fingernails short and clean } \\
\hline Yes & 157 & 42.2 \\
\hline No & 215 & 57.8 \\
\hline \multicolumn{3}{|l|}{ Children mouthed soil material } \\
\hline Yes & 247 & 66.4 \\
\hline No & 125 & 33.6 \\
\hline
\end{tabular}


Table 3 Waste management practices of the rural households in the east Dembiya district, northwest Ethiopia, May-June 2021, $(n=372)$

\begin{tabular}{lcc}
\hline Waste management related variables & Frequency & Percent \\
\hline Defecation practice of household members & 242 & 65.1 \\
Open field & 130 & 34.9 \\
Traditional pit latrine & 53 & 14.2 \\
How the household manage domestic waste water & \\
Use soak pit & 319 & 85.8 \\
Disposed everywhere in the yard & & \\
How the household manage rubbish & 276 & 74.2 \\
Open dumping & 79 & 21.2 \\
Burning & 17 & 4.6 \\
Burial & & \\
Animal excreta in the living environment & 272 & 73.1 \\
Yes & 100 & 26.9 \\
No &
\end{tabular}

domestic waste water everywhere in the yard. Two hundred and seventy-six (74.2\%) of the rural households disposed of rubbish in the open field. Furthermore, animal excreta in the living environments was observed among $272(73.1 \%)$ the rural households (Table 3 ).

\section{Drinking water supply and safety measures}

The drinking water source for 283 (76.1\%) of the households was ground water. One hundred and ninety-six (52.7\%) of the households collected drinking water from unprotected sources (rivers, unprotected springs, or unprotected wells). One hundred forty-two (38.2\%) of the households reported that their water sources are intermittent, and 78 (21.0\%) of the households reported that they had to travel more than $1 \mathrm{~km}$ to access water sources. Vast majority, $299(80.4 \%)$ of the households collected less than $20 \mathrm{l} / \mathrm{c} / \mathrm{d}$ of water. Two hundred and eighty-four $(76.3 \%)$ of the households stored water in narrow mouthed containers. At the time of the survey, the water storage containers in 166 (44.6\%) and 129 (34.7\%) of the households were not clean and covered, respectively. The drinking water in $59(15.9 \%)$ of the households was turbid. Only 14 (3.8\%) of the households reported that they are practicing home-based water treatment (Table 4).

\section{Food safety measures}

Two hundred and ninety-six (79.6\%) of the households reported that they always washed food utensils with soap or ash, and 100 (26.9\%) of the households reported that they used a perforating rack to dry washed utensils. Three hundred and thirty-five (90.1\%) of the households
Table 4 Access to drinking water sources and water handling practices in the rural households in the east Dembiya, northwest Ethiopia, May-June 2021, ( $n=372)$

\begin{tabular}{|c|c|c|}
\hline Drinking water supply related variables & Frequency & Percent \\
\hline \multicolumn{3}{|l|}{ Drinking water sources } \\
\hline Ground water & 283 & 76.1 \\
\hline Surface water & 89 & 23.9 \\
\hline \multicolumn{3}{|l|}{ Drinking water sources } \\
\hline Protected & 176 & 47.3 \\
\hline Unprotected & 196 & 52.7 \\
\hline \multicolumn{3}{|c|}{ Water sources provide water throughout the year } \\
\hline Yes & 230 & 61.8 \\
\hline No & 142 & 38.2 \\
\hline \multicolumn{3}{|c|}{ How far the water sources located from the dwelling } \\
\hline Within $1 \mathrm{~km}$ radius & 294 & 79.0 \\
\hline More than $1 \mathrm{~km}$ away & 78 & 21.0 \\
\hline \multicolumn{3}{|l|}{ Volume of water collected } \\
\hline$<20 \mathrm{l} / \mathrm{c} / \mathrm{d}$ & 299 & 80.4 \\
\hline$\geq 20 \mathrm{l} / \mathrm{c} / \mathrm{d}$ & 73 & 19.6 \\
\hline \multicolumn{3}{|l|}{ Type of water storage containers } \\
\hline Narrow mouthed containers & 284 & 76.3 \\
\hline Wide mouthed containers & 88 & 23.7 \\
\hline \multicolumn{3}{|l|}{ Water storage containers are clean } \\
\hline Yes & 206 & 55.4 \\
\hline No & 166 & 44.6 \\
\hline \multicolumn{3}{|c|}{$\begin{array}{l}\text { The water storage containers are properly covered at the time of the } \\
\text { survey }\end{array}$} \\
\hline Yes & 243 & 65.3 \\
\hline No & 129 & 34.7 \\
\hline \multicolumn{3}{|l|}{ The water is turbid } \\
\hline Yes & 59 & 15.9 \\
\hline No & 311 & 84.1 \\
\hline \multicolumn{3}{|l|}{ Homebased water treatment } \\
\hline No & 358 & 96.2 \\
\hline Water guard & 6 & 1.6 \\
\hline Boiling & 8 & 2.2 \\
\hline
\end{tabular}

reported that they thoroughly cooked foods. One hundred and seventy-two (46.2\%) and $160(44.0 \%)$ of the mothers or care givers reported that they did not touch their body or other things while preparing food, and did not prepare food while they were experiencing diarrhea or vomiting, respectively. One hundred and fifty-eight $(42.5 \%)$ of the households reported giving leftover foods to children and 119 of 158 (75.3\%) households reheated leftover foods before use. Results from the observation indicated that food utensils containing foods were clean in 225 (60.5\%) of the households, covered properly in 233 (62.6\%) of the households, stored in clean area or shelf in 199 (53.5\%) of the households, were accessible to pets in 118 (31.7\%) of the households, and mechanical vectors 
Table 5 Food safety practices of the rural households in the east Dembiya district, northwest Ethiopia, May-June 2021, (n=372)

\begin{tabular}{|c|c|c|}
\hline Food safety measures & Frequency & Percent \\
\hline \multicolumn{3}{|c|}{ Always washed food utensils with soap or ash } \\
\hline Yes & 296 & 79.6 \\
\hline No & 76 & 20.4 \\
\hline \multicolumn{3}{|c|}{ How do you dry washed food utensils } \\
\hline Perforating rack & 100 & 26.9 \\
\hline Wipe with cloth & 46 & 12.4 \\
\hline Dry in the air & 226 & 60.8 \\
\hline \multicolumn{3}{|c|}{ Thoroughly cooked foods to be cooked } \\
\hline Yes & 335 & 90.1 \\
\hline No & 37 & 9.9 \\
\hline \multicolumn{3}{|c|}{ Does not touch body and other things while preparing foods } \\
\hline Yes & 172 & 46.2 \\
\hline No & 200 & 53.8 \\
\hline \multicolumn{3}{|c|}{ Prepare foods while you have diarrhea/or vomiting or other enteric infections } \\
\hline Yes & 212 & 57.0 \\
\hline No & 160 & 43.0 \\
\hline \multicolumn{3}{|c|}{ Provide leftover foods to children } \\
\hline Yes & 158 & 42.5 \\
\hline No & 214 & 57.5 \\
\hline \multicolumn{3}{|c|}{ Reheat leftover foods before serving $(n=158)$} \\
\hline Yes & 119 & 75.3 \\
\hline No & 39 & 24.7 \\
\hline \multicolumn{3}{|c|}{ Food utensils containing foods are clean during the survey } \\
\hline Yes & 225 & 60.5 \\
\hline No & 147 & 39.5 \\
\hline \multicolumn{3}{|c|}{ Food utensils containing foods are covered properly during the survey } \\
\hline Yes & 233 & 62.6 \\
\hline No & 139 & 37.4 \\
\hline \multicolumn{3}{|c|}{ Food utensils containing foods are stored in clean area or shelf during the survey } \\
\hline Yes & 199 & 53.5 \\
\hline No & 173 & 46.5 \\
\hline \multicolumn{3}{|c|}{ Food utensils containing foods are accessible to pets } \\
\hline Yes & 118 & 31.7 \\
\hline No & 254 & 68.3 \\
\hline \multicolumn{3}{|c|}{ Vectors or rodents are seen in food storage areas } \\
\hline Yes & 244 & 65.6 \\
\hline No & 128 & 34.4 \\
\hline
\end{tabular}

or rodents were seen around food storage areas in 244 (65.6\%) of the households (Table 5).

\section{Detection of $E$. coli in water, food and soil}

Figure 1 shows $E$. coli counts recovered in drinking water at point of use, ready-to-eat foods, and courtyard soil. $E$. coli was detected in 257 (69.1\%) of the water samples at point of use. The lowest and highest $E$. coli counts recovered were 1 and 1613 CFU per $100 \mathrm{ml}$, respectively with a mean $E$. coli count of 273.37 CFU. The water quality of $90(24 \%)$ and $27(7 \%)$ of the households was at high and very high-risk level, respectively (Fig. 2A). Similarly, $E$. coli was detected in 251 (67.5\%) of the food samples. The lowest and highest $E$. coli counts recovered were 1 and 1500 CFU per g, respectively with a mean $E$. coli count of 184.88 CFU. The microbial quality of ready-to-eat foods was, therefore, found to be unsatisfactory in 68 (18.3\%) of the rural households (Fig. 2B). Three hundred and nine (83.1\%) of the soil samples were found to be positive for 
100

90

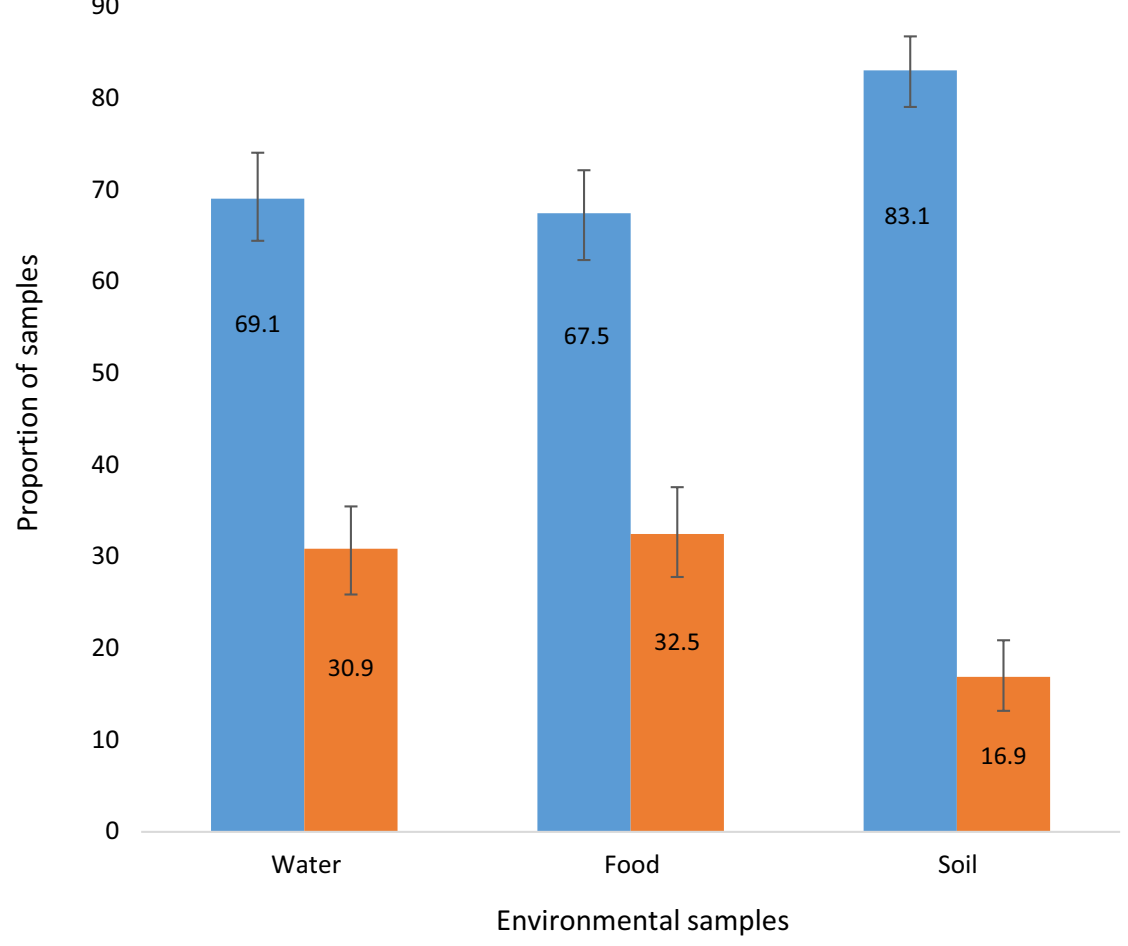

Fig. 1 Proportion of positive and negative water, food and soils samples for E. coli in the rural households of the east Dembiya district, northwest Ethiopia, May-June 2021, ( $n=372)$. Error bars indicate the 95\% Cl for proportion

Positive Negative 


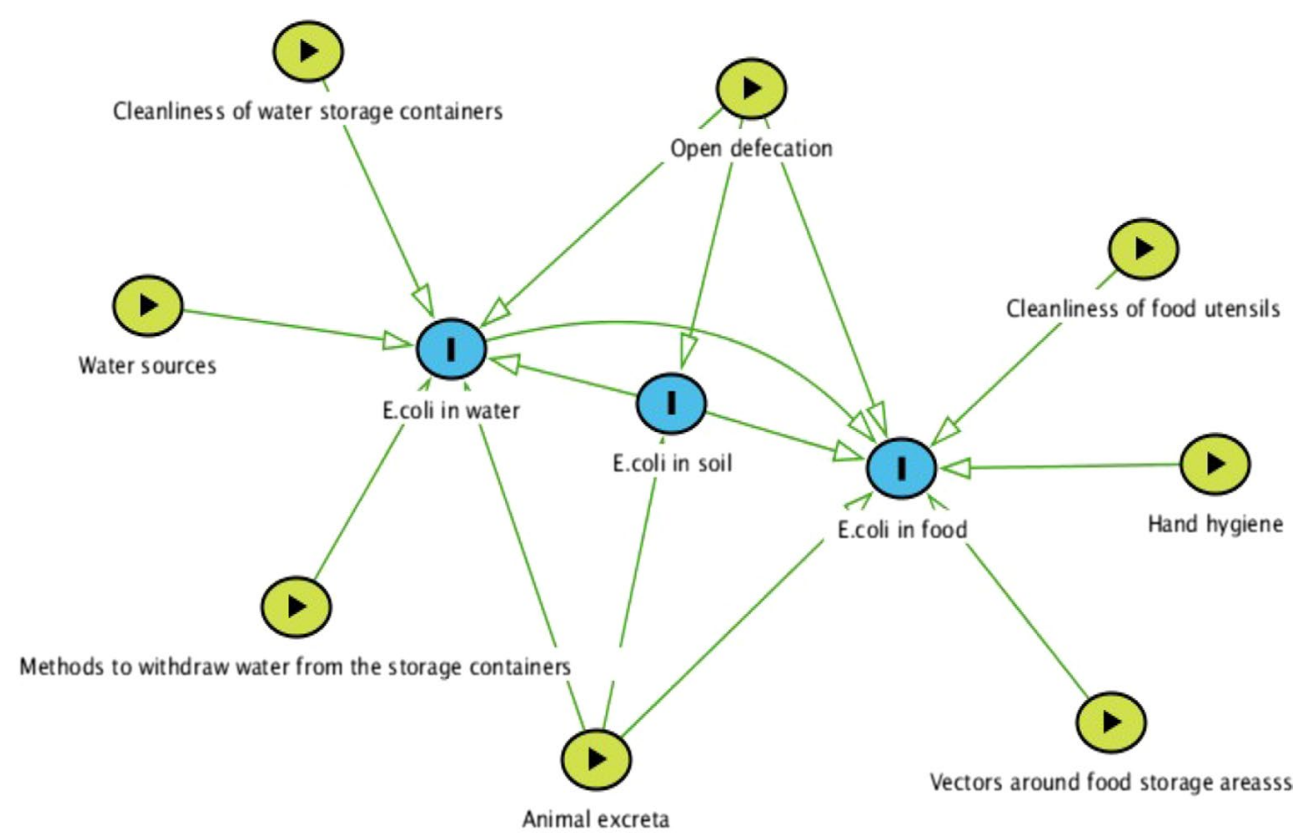

\section{Exposure variables}

Outcome variables

Fig. 3 Exposure pathways of E. coli contamination along the environmental compartments. The chart is drawn using Dagitty software from the results of a linear regression analysis done to see the associations between contamination levels of environmental exposure pathways along another pathways. Arrows indicate associations that are significant $(p<0.05)$; the lack of an arrow between two sample types indicates that we did not observe a significant association

E. coli. The lowest and highest E. coli counts recovered were 20 and 3200 CFU per g, respectively with a mean $E$. coli count of 739.18 CFU.

\section{E. coli contamination pathways in soil, water, and food}

Figure 3 illustrates the pathways of E. coli contamination along the three environmental compartments (water, food, and soil). Number of E. coli counts in CFU recovered from courtyard soil in child playing areas was associated with open defecation practice ( $\beta: 188.6,95 \%$ CI $(64.0,313.1)$ and presence of animal excreta in the living environment ( $\beta$ : 592.6, 95\% CI (470.7, 714.4). E. coli counts recovered in drinking water was explained by $E$. coli contamination of soil ( $\beta$ : 227.4, 95\% CI (132.6, 322.1 ), open defecation practice ( $\beta: 127.8,95 \%$ CI (53.6, $202.0)$, presence of animal excreta in the living environment ( $\beta$ : 126.4, 95\% CI $(43.8,209.1)$, unprotected water sources $(\beta: 19.2,95 \%$ CI $(32.5,205.8)$, unclean water storage containers ( $\beta$ : 100.0, 95\% CI $(27.1,172.9)$, and dipping of mugs to withdraw water from the storage containers $(\beta$ : $187.0,95 \%$ CI $(90.7,283.4)$. E. coli counts recovered in ready-to-eat foods was also associated with open defecation practice $(\beta: 71.5,95 \% \mathrm{CI}$ $(1.6,141.4)$, presence of animal excreta in the living environment ( $\beta$ : 94.2, 95\% CI $(19.9,168.5)$, availability of mechanical vectors around food storage areas $(\beta$ : 108.6, 95\% CI $(43.1,174.2)$, unclean food utensils $(\beta$ : $108.8,95 \%$ CI $(43.7,173.8)$, poor hand hygiene of persons who prepared or served foods ( $\beta$ : $104.4,95 \% \mathrm{CI}$ (37.8, 170.9), E. coli contamination of soil ( $\beta$ : 91.5, 95\% CI $(4.6,178.4)$, and $E$. coli contamination of water $(\beta$ : $76.7,95 \%$ CI $(6.2,147.2)$.

\section{Intestinal parasites in children}

A total of 372 children were examined, with 178 (47.8\%) (95\% CI: $42.8,52.6 \%$ ) of them had ova of one or more intestinal parasites. The commonest intestinal parasites identified among children were $A$. lumbricoides [77 (20.7\%)], S. mansoni [71 (19.1\%)], H. nana [19 (5.1\%)], Hookworm [17 (4.6\%)], and E. histolytica [14 (3.8\%) (Fig. 4). The intensity of $S$. mansoni was moderate and heavy among $25(6.7 \%)$ and $5(1.3 \%)$ of the children, respectively (Table 6).

\section{Environmental predictors of intestinal parasites in children} The multilevel (intercept-only) model represents a significant improvement in fit relative to a standard binary logistic regression. The chi-square test indicates the difference in fit is significant between models, $\chi^{2}(1)=58.31$, 
30

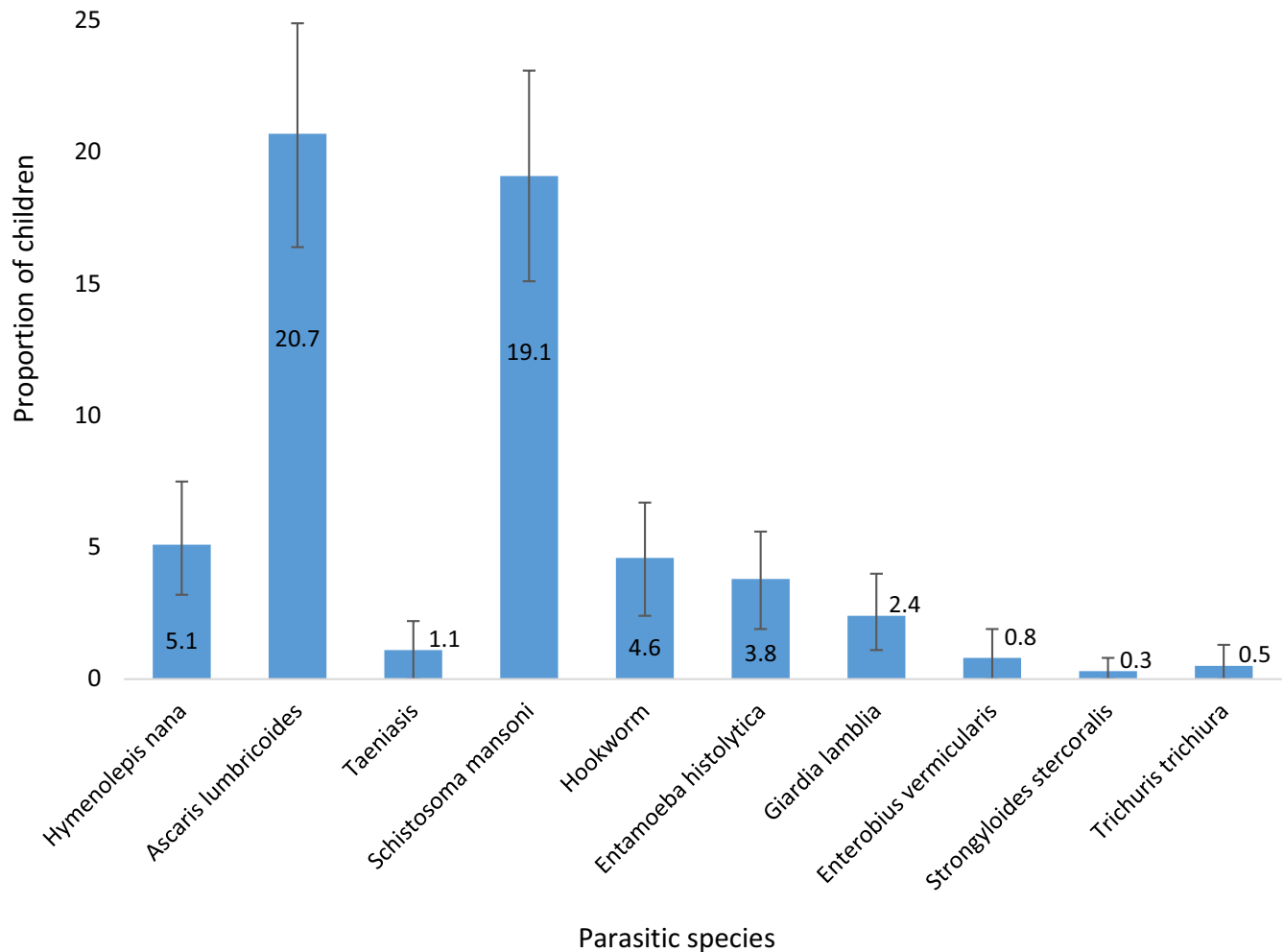

Fig. 4 Common intestinal parasites identified among children aged 24-59 months in the rural settings of the east Dembiya district, northwest Ethiopia, May-June 2021, $(n=372)$. Error bars indicate the $95 \% \mathrm{Cl}$ for proportion of parasitic species

Table 6 Mean number of eggs per gram of stool quantified with minimum and maximum number and intensity of intestinal parasites in children aged 24-59 months in the rural settings of the east Dembiya district, northwest Ethiopia, May-June 2021, ( $n=372)$

\begin{tabular}{|c|c|c|c|c|}
\hline \multirow[t]{2}{*}{ Parasitic species } & \multirow{2}{*}{$\begin{array}{l}\text { Mean number of eggs per gram of stool } \\
\text { (minimum and maximum) }\end{array}$} & \multicolumn{3}{|c|}{ Number of children with } \\
\hline & & Light intensity & Moderate intensity & $\begin{array}{l}\text { Heavy } \\
\text { intensity }\end{array}$ \\
\hline A. lumbricoides & $1725(48,12,560)$ & 70 & 7 & 0 \\
\hline Hookworm & $95(48,384)$ & 17 & 0 & 0 \\
\hline S.mansoni & $217(24,3456)$ & 41 & 25 & 5 \\
\hline H. nana & $489(48,6480)$ & 18 & 1 & 0 \\
\hline T. trichiura & $252(120,384)$ & 2 & 0 & 0 \\
\hline
\end{tabular}

$p<0.001$. The intra-class correlation coefficient (ICC) also shows that there was substantial clustering effect on exposure of children to intestinal parasites. Table 7 illustrates that the community variance in intestinal parasites in children was estimated at $38 \%$. It means that $38 \%$ of the residual variation in the exposure of children to intestinal parasites is attributable to unobserved community characteristics.

The coefficient model shows that exposure to intestinal parasites was higher among older children compared to young children (AOR 2.18, 95\% CI (1.01, 4.68). The odds of having intestinal parasites was 1.98 times higher in children whose mothers did not keep their fingernails 
Table 7 Multilevel binary logistic regression results on the environmental predictors of exposure of children to intestinal parasites in the rural settings of the east Dembiya district, northwest Ethiopia, May 2021

\begin{tabular}{|c|c|c|c|c|}
\hline Variables & Null model & Intermediate model & Coefficient model & $\begin{array}{l}\text { Cross-level } \\
\text { interaction model }\end{array}$ \\
\hline \multicolumn{5}{|l|}{ Age of children in months } \\
\hline 24-36 months & & 1.0 & 1.0 & 1.0 \\
\hline $37-48$ months & & $2.16(1.02,4.58)^{*}$ & $2.18(1.01,4.68)^{*}$ & $2.15(1.01,4.58)^{*}$ \\
\hline 49-59 months & & $1.46(0.69,3.06)$ & $1.63(0.76,3.49)$ & $1.45(0.69,3.05)$ \\
\hline \multicolumn{5}{|c|}{ Mothers or care givers kept finger nails short and clean } \\
\hline Yes & & 1.0 & 1.0 & 1.0 \\
\hline No & & $1.93(1.04,3.57)^{*}$ & $1.98(1.07,3.66)^{*}$ & $1.99(1.07,3.69)^{*}$ \\
\hline \multicolumn{5}{|c|}{ Children kept finger nails short and clean } \\
\hline Yes & & 1.0 & 1.0 & 1.0 \\
\hline No & & $3.15(1.75,5.69)^{* * *}$ & $3.20(1.77,5.77)^{* * *}$ & $3.24(1.79,5.85)^{* * *}$ \\
\hline \multicolumn{5}{|c|}{ Mouthing of soil contaminated materials } \\
\hline Yes & & $2.21(1.21,4.02)^{* *}$ & $2.31(1.26,4.24)^{* *}$ & $2.30(1.26,4.18)^{* *}$ \\
\hline No & & 1.0 & 1.0 & 1.0 \\
\hline \multicolumn{5}{|c|}{ Defecation practice of households } \\
\hline Open field & & $2.18(1.18,4.01)^{*}$ & $2.22(1.20,4.10)^{*}$ & $2.31(1.24,4.30)^{* *}$ \\
\hline Latrine & & 1.0 & 1.0 & 1.0 \\
\hline \multicolumn{5}{|c|}{ Animal excreta in the living environment } \\
\hline Yes & & $1.52(0.81,2.83)$ & $1.64(0.87,3.11)$ & $1.54(0.82,2.88)$ \\
\hline No & & 1.0 & 1.0 & 1.0 \\
\hline \multicolumn{5}{|c|}{ Volume of water a family collected per day } \\
\hline$<20 \mathrm{l} / \mathrm{c} / \mathrm{d}$ & & $2.47(1.18,5.18)^{*}$ & $2.38(1.13,5.01)^{*}$ & $2.52(1.21,5.26)^{*}$ \\
\hline$\geq 20 \mathrm{l} / \mathrm{c} / \mathrm{d}$ & & 1.0 & 1.0 & 1.0 \\
\hline \multicolumn{5}{|c|}{ E. coli detected in courtyard soil samples } \\
\hline Yes & & $2.52(1.31,483)^{* *}$ & $2.56(1.34,4.90)^{* *}$ & $2.48(1.29,4.75)^{* *}$ \\
\hline No & & 1.0 & 1.0 & \\
\hline \multicolumn{5}{|c|}{ E. coli detected in ready-to-eat food samples } \\
\hline Yes & & $3.09(1.65,5.79)^{* * *}$ & $3.21(1.69,6.09)^{* * *}$ & $3.17(1.68,5.98)^{* * *}$ \\
\hline No & & 1.0 & 1.0 & 1.0 \\
\hline \multicolumn{5}{|c|}{ E. coli detected in drinking water samples } \\
\hline Yes & & $2.51(1.31,4.80)^{* *}$ & $1.88(0.68,5.22)$ & $5.30(1.89,14.85)^{* *}$ \\
\hline No & & 1.0 & 1.0 & 1.0 \\
\hline \multicolumn{5}{|c|}{ Vectors observed in the food storage areas } \\
\hline Yes & & $1.09(0.60,1.98)$ & $1.12(0.62,2.03)$ & $1.14(0.62,2.07)$ \\
\hline No & & 1.0 & 1.0 & 1.0 \\
\hline \multicolumn{5}{|c|}{ Drinking water sources (2nd level predictor) } \\
\hline Protected & & 1.0 & 1.0 & 1.0 \\
\hline Unprotected & & $1.81(0.37,8.82)$ & $0.70(0.22,2.19)$ & $1.26(0.26,5.97)$ \\
\hline \multicolumn{5}{|c|}{ Drinking water source ${ }^{*} E$. coli detected in water samples at point of use } \\
\hline Protected*No & & & & 1.0 \\
\hline Unprotected*Yes & & & & $3.83(1.01,14.46)^{*}$ \\
\hline \multicolumn{5}{|l|}{ Random effects } \\
\hline Coefficient variance (SE) & & & $0.15(0.65)$ & \\
\hline Community level variance (SE) & $2.03(1.05)$ & $2.35(1.30)$ & $2.14(2.24)$ & $2.13(1.20)$ \\
\hline Covariance (SE) & & & $-0.56(1.51)$ & \\
\hline Log-likelihood & $58.31(p<0.001)$ & $33.36(p<0.001)$ & $37.81(p<0.001)$ & $29.33(p<0.001)$ \\
\hline ICC & 0.38 & 0.42 & 0.04 & 0.39 \\
\hline AIC & 460.71 & 392.46 & 392 & 390.38 \\
\hline
\end{tabular}

Note: * statistically significant variables at $p<0.05,{ }^{* *}$ statistically significant variables at $p<0.01$, and ${ }^{* * *}$ statistically significant variables at $p<0.001$ 
short and clean (AOR 1.98, 95\% CI $(1.07,3.66)$. Children who didn't keep their fingernails short and clean had also higher odds to have intestinal parasites compared with their counterparts (AOR 3.20, 95\% CI (1.77, 5.77). In addition, the odds of having intestinal parasites was 2.31times higher in children who mouthed soil contaminated materials (AOR 2.31, 95\% CI $(1.26,4.24)$ (Table 7).

Furthermore, children who lived in families who practiced open defecation had higher exposure to intestinal parasites compared with children who lived in families who used latrine (AOR 2.22, 95\% CI $(1.20,4.10)$. The odds of having intestinal parasites was also 2.38 times higher among children who lived in families with no basic access to drinking water (AOR 2.38, 95\% CI (1.13, 5.01 ) and poor water quality was significantly associated with exposure to intestinal parasites (AOR 2.51, 95\% CI (1.31, 4.80). The bacteriological quality of ready-to-eat foods was also significantly associated with high burden of intestinal parasites in children (AOR 3.21, 95\% CI $(1.69,6.09)$. Similarly, poor bacteriological quality of courtyard soil was associated with increased probability of exposure of children to intestinal parasites (AOR 2.56, 95\% CI $(1.34,4.90)$ (Table 7).

The cross-level interaction model shows that there is evidence of effect modification of the association between bacteriological quality of drinking water at point of use and exposure of children to intestinal parasites by water sources. For children in households whose drinking water quality is poor, having unprotected water sources (versus protected sources) results in a 3.83 times higher chance of having intestinal parasites (AOR 3.83, 95\% CI $(1.01,14.46)$ (Table 7).

\section{Discussion}

This community-based cross-sectional study with structured observation and laboratory investigations was conducted in the rural settings of northwest Ethiopia to assess environmental exposures of children to intestinal parasites. An extensive E. coli contamination of environmental compartments, including drinking water, ready-to-eat foods and courtyard soil from children's outdoor play area was observed. Although the WHO standard for drinking water quality is $0 \mathrm{CFU}$ of E. coli per $100 \mathrm{ml}$ of drinking water [20], we found that the E. coli counts in $69.1 \%$ of the households exceeded the WHO standard with a mean $E$. coli count of $273.37 \mathrm{CFU}$ per $100 \mathrm{ml}$. Other studies also reported high $E$. coli contamination of water at household level [27-31]. This high E.coli contamination of water can be explained by poor sanitation condition in the area and poor water handling practices at individual households. As we documented in this study, open defecation and animal excreta were common in the study area, which could cause contamination of drinking water at the source. Pathogens in the contaminated environment or soil can reach to water sources by the help of flood, wind, and animals [32-35]. Moreover, types and cleanliness of water storage containers, methods of withdrawing water from the storage containers, and sanitation condition of the storage areas are risk factors for contamination of water at household level [36-38]. As documented in this study, water storage containers in $44.6 \%$ of households were not clean and not properly covered in $34.7 \%$ of the households, and $96.2 \%$ of the households did not practiced home-based water treatment.

In the current study, $83.1 \%$ of the courtyard soil samples from child playing areas were positive for $E$. coli with a mean E. coli count of $739.18 \mathrm{CFU}$ per g. Other studies in developing countries also reported high $E$. coli contamination of courtyard soil [39-42]. Two major factors explained the high $E$. coli contamination: presence of animal excreta in the living environment and open defecation. Studies done in low and middle income countries also suspected animal excreta as a contributor to fecal contamination [43-46]. In the study area domestic animals and their feces are not properly contained or separated from domestic environments. Domestic animals generate $85 \%$ of the world's animal fecal waste, a far greater proportion than the human population, resulting in fecal contamination of soil due to insufficient separation of animal feces from human domestic environments [47]. Despite the fact that adult family members may not defecate openly in the courtyard, child feces was observed in a significant proportion of rural households, which could lead E. coli contamination of courtyard soil. Furthermore, because two-thirds of the households in the study area defecated openly, i.e., near bushes in the living environment, feces could reach the courtyard soil via animals, wind, and flood, resulting $E$. coli contamination of the courtyard soil. Even if a single infected animal may excrete more pathogens than a single human [4749], $1 \mathrm{~g}$ of fresh feces from an infected person can contain around $10^{6}$ viral pathogens, $10^{6}-10^{8}$ bacterial pathogens, $10^{4}$ protozoan cysts, and10-10 4 helminth eggs [50].

E. coli contamination of ready-to-eat foods was reported in $67.5 \%$ of the food samples collected from individual households with a mean $E$. coli count of 184.88 CFU/g, which indicated that the food in more than two-third of the households was contaminated. Other similar studies also reported high E. coli contamination of foods like our study [42, 51-54]. The E. coli counts recovered in $37 \%$ of the rural households were higher than the microbiological standards of ready-to-eat foods [22, 55]. Findings of the current study suggest that open defecation practice, presence of animal excreta in 
the living environment, availability of vectors in/around food storage areas, unclean food utensils, and poor hand hygiene of persons who prepared or served foods, $E$. coli contamination of soil, and $E$. coli contamination of water all significantly contribute to $E$. coli contamination of ready-to-eat foods. Foods may not be directly exposed to primary contaminants, i.e., fecal matters, rather fecal matters make their way into foods because of poor personal hygiene of food handlers, contaminated water, and vectors like flies and rodents. This exposure pathways are widely documented in literature [54, 56-58].

The extensive contamination of the home environment (drinking water, ready-to-eat foods and courtyard soil) was strongly associated with exposure of children to intestinal parasites. Ova of one or more intestinal parasites was detected in $47.8 \%$ (95\% CI $42.8,52.6 \%$ ) of the children, which is high compared with reports of community-based studies among under-five children in different parts of Ethiopia, such as in Chuahit (35.2\%) [15], Goncha Siso Enese (11.8\%) [59], Wonji Shoa (24.3\%) [60], and Butajira (23.3\%) [61]. Moreover, the burden of intestinal parasites reported in the current study is higher compared to findings of studies in other developing countries, such as in Kenya (25.6\%) [62], India (17.0\%) [63], Mozambique (31.6\%) [64], and Nigeria (23.3\%) [65]. The high burden of intestinal parasites in children is linked to extensive E. coli contamination water, ready-toeat foods and courtyard soil from children's outdoor play area. Fecal contamination of foods, water and soil plays a greater role in fecal-oral transmission [66].

This study also revealed that the high burden of intestinal parasites in children in the rural northwest Ethiopia was significantly associated with open defecation practice and poor hand hygiene condition of mothers or care givers and children and mouthing of soil contaminated materials. Open defecation causes fecal contamination of soil. Cross-contamination of water and foods occurs as a result of fecally contaminated soil [18, 67-69]. In addition, fecally contaminated soil creates favorable conditions for multiplication of mechanical vectors that carry pathogens from contaminated soil to food [70-72]. Contaminated soil also causes contamination of hands with fecal matter while playing or doing day-to-day activities [73, 74]. Children get sick from contaminated hands if they don't wash hands frequently with soap and keep their fingernails short. The area beneath the fingernails has the highest concentration of microorganisms on the hands and is the most difficult to clean [75-78]. Mouthing of soil contaminated materials is also the other direct impact of fecally contaminated soil in exposure to intestinal parasites. Children may ingest diseases causing pathogens when they mouthed soil contaminated materials [41, 79-81]. According to findings of this study, children who mouthed soil contaminated materials had a higher risk of exposure to intestinal parasites. Furthermore, lack of access to water for personal hygiene in the area increases the risk of exposure to intestinal parasites through contaminated hands from fecally contaminated soil $[82,83]$. This study discovered that children who lived in families with no basic access to drinking water, i.e., less than $20 \mathrm{l} / \mathrm{c} / \mathrm{d}$, had a higher risk of exposure to intestinal parasite.

As a limitation, the burden of intestinal parasites was measured in the dry season. The associations reported in the current study are not adjusted for seasonal variations. We, therefore, recommend other large scale study to clearly show the seasonal variations. Moreover, there might be errors in quantification of ova of parasites because of variation in ova distribution in stool samples. To minimize this error, the preparation was primarily smeared evenly based on the standard to increase the quality of detection and quantification. The self-reported data may not be reliable since the study subjects may make the more socially acceptable answer rather than being truthful and they may not be able to assess themselves accurately. The generalizability of the results may be affected since contamination may vary in different settings.

\section{Conclusion}

An extensive E. coli contamination of water, foods, and courtyard soil was found in the studied region and the potential sources of contamination were open defecation practices, unhygienic disposal of wastes, poor animal husbandry and keeping practices, and poor water and food safety measures at household level. Moreover, fecal contamination of water, foods, and soil linked to a high burden of intestinal parasites among children in the studied region, which indicates children in the rural northwest Ethiopia had multiple exposure pathways to intestinal parasites. Administration of anthelminthic drugs to the infected children is important to expel parasitic worms and other internal parasites from the body. Moreover, implementing both individual-level intervention (such as construction and utilization of latrine, safe disposal of wastes, food safety, hand hygiene promotion, household water treatment, and containment of domestic animals and their excreta) and community-level interventions (such as protecting water sources from fecal contamination, source-based water treatment, community-driven sanitation, and WASH behavior change communication) is important to protect the environment from contamination and to prevent child exposure to intestinal parasites and transmission. In general, integrating preventive chemotherapy with WASH interventions to have the greatest impact towards prevention and 
control of intestinal parasites in the area should be the priority of the local healthcare system as reinfections can be rapid due to the complex nature of exposures.

\begin{abstract}
Abbreviations
AIC: Akaike information criterion; CFU: Colony forming units; Cl: Confidence interval; CVR: Content validity ratio; E. coli: Escherichia coli; EPG: Eggs per gram; DAG: Direct acyclic graph; ICC: Intraclass correlation coefficient; I-CVI: Itemlevel content validity index; l/c/d: Liter per capita per day; ml: Milliliter; PBW: Peptone-buffered water; S-CVI/UA: Universal agreement scale -level content validity index; SD: Standard deviation; STHs: Soil-transmitted helminth infections; WASH: Water, sanitation and hygiene; WHO: World health organization.
\end{abstract}

\section{Acknowledgements}

The authors are pleased to acknowledge the University of Gondar, One Health Eastern Africa Research Training (OHEART) program at the Ohio State University, Global One Health Initiative $(\mathrm{GOHi})$ and National Institutes of Health $(\mathrm{NIH})$ Fogarty International Center for their support.

\section{Authors' contributions}

ZG designed the study, conducted data analysis and produced the initial draft of the manuscript. BDB supervised data collection. AWY, JL and MB contributed to conceptualizing the study. All authors read and approved the final manuscript.

\section{Funding}

This study is funded by One Health Eastern Africa Research Training (OHEART) programe at the Ohio State University, Global One Health Initiative (GOHi) through National Institutes of Health $(\mathrm{NIH})$ Fogarty International Center (grant number TW008650) and the University of Gondar (grand number R/T/T/C/ Eng./300/08/2019).

\section{Availability of data and materials}

Data will be made available upon requesting the primary author.

\section{Declarations}

\section{Ethics approval and consent to participate}

Ethical clearance was obtained from the Institutional Review Board of the University of Gondar (reference number: V/P/RCS/05/1933/2020). There were no risks due to participation and the collected data were used only for this research purpose with complete confidentiality. Written informed consent was obtained from mothers or care givers. All the methods were carried out in accordance with relevant guidelines and regulations.

\section{Consent for publication}

This manuscript does not contain any individual person's data.

\section{Competing interests}

The authors declared that there is no conflict of interest or financial disclosure about this publication.

\section{Author details}

${ }^{1}$ Department of Environmental and Occupational Health and Safety, Institute of Public Health, College of Medicine and Health Sciences, University of Gondar, Gondar, Ethiopia. ${ }^{2}$ Addis Continental Institute of Public Health, Addis Ababa, Ethiopia. ${ }^{3} \mathrm{Global}$ One Health Initiative (GOHi), The Ohio State University, Columbus, OH, USA. ${ }^{4}$ School of Public Health, Addis Ababa University, Addis Ababa, Ethiopia. ${ }^{5}$ Division of Environmental Health Sciences, College of Public Health, The Ohio State University, 1841 Neil Avenue, Columbus, $\mathrm{OH} 43210$, USA. ${ }^{6}$ Department of Food Science and Technology, The Ohio State University, Columbus, OH, USA.

Received: 7 October 2021 Accepted: 21 February 2022

Published online: 27 February 2022

\section{References}

1. IHME: Global Burden of Disease Collaborative Network. Global Burden of Disease Study 2016 (GBD 2016) Results. Institute for Health Metrics and Evaluation Seattle; 2017. http://ghdx.healthdata.org/record/ihmedata/gbd-2016-all-cause-under-5-mortality-adult-mortality-and-lifeexpectancy-1970-2016. Accessed 12 Aug 2021.

2. WHO: Soil-transmitted Helminth infections. 2020. https://www.who. int/news-room/fact-sheets/detail/soil-transmitted-helminth-infections. Accessed 10 Aug 2021.

3. World Health Organization Regional Office for Africa. Helminthiasis. https://www.afro.who.int/health-topics/helminthiasis. Accessed 08 Dec 2021.

4. Negussu N, Mengistu B, Kebede B, Deribe K, Ejigu E, Tadesse G, Mekete K, Sileshi M. Ethiopia schistosomiasis and soil-transmitted helminthes control programme: progress and prospects. Ethiop Med J. 2017;55(Suppl 1):75

5. Hailegebriel T. Prevalence of intestinal parasitic infections and associated risk factors among students at Dona Berber primary school, Bahir Dar, Ethiopia. BMC Infect Dis. 2017;17(1):1-8.

6. Kagan LJ, Aiello AE, Larson E. The role of the home environment in the transmission of infectious diseases. J Community Health. 2002;27(4):247-67.

7. Goddard FG, Ban R, Barr DB, Brown J, Cannon J, Colford JM Jr, Eisenberg $\mathrm{JN}$, Ercumen A, Petach $\mathrm{H}$, Freeman MC. Measuring environmental exposure to enteric pathogens in low-income settings: review and recommendations of an interdisciplinary working group. Environ Sci Technol. 2020;54(19):11673-91.

8. Edberg S, Rice E, Karlin R, Allen M. Escherichia coli: the best biological drinking water indicator for public health protection. J Appl Microbiol. 2000;88(S1):106S-116S.

9. Brown J, Cumming O. Stool-based pathogen detection offers advantages as an outcome measure for water, sanitation, and hygiene trials. Am J Trop Med Hyg. 2020;102(2):260.

10. Robb K, Null C, Teunis P, Yakubu H, Armah G, Moe CL. Assessment of fecal exposure pathways in low-income urban neighborhoods in Accra, Ghana: rationale, design, methods, and key findings of the SaniPath study. Am J Trop Med Hyg. 2017;97(4):1020.

11. Raj SJ, Wang Y, Yakubu H, Robb K, Siesel C, Green J, Kirby A, Mairinger W, Michiel J, Null C. The SaniPath Exposure Assessment Tool: A quantitative approach for assessing exposure to fecal contamination through multiple pathways in low resource urban settlements. PLOS ONE. 2020;15(6):e0234364

12. East Dembiya District Health Department: Plan and Monitoring Office annual report 2020, by Melese Eshetie and others, Koladiba: Officer of district health department plan and monitoring office, Amhara region, Ethiopia. 2020

13. Dembiya District Finance and Economic Development Office: annual report, by Zewudu Fetene and others, Koladiba: Officer of finance and economic development, Amhara region, Ethiopia. 2017.

14. Dembiya District Health Office: annual report, by Tsigereda Kefale and others, Koladiba: officer of district health office, Amhara Region, Ethiopia. 2017

15. Alemu A, Tegegne Y, Damte D, Melku M. Schistosoma mansoni and soil-transmitted helminths among preschool-aged children in Chuahit, Dembia district, Northwest Ethiopia: prevalence, intensity of infection and associated risk factors. BMC Public Health. 2016;16(1):1-9.

16. Deressa W, Hailemariam D, Ali A. Economic costs of epidemic malaria to households in rural Ethiopia. Trop Med Int Health. 2007;12(10):1148-56.

17. Hasen A. Census Mapping In Ethiopia. Symposium on Global Review of 2000 Round of Population and Housing Censuses: Mid-Decade Assessment and Future Prospects Statistics Division. Department of Economic and Social Affairs, United Nations Secretariat. New York, 7-10 August 2001. https://unstats.un.org/unsd/demog/docs/symposium_39.htm. Accessed 12 May 2016.

18. Sclar GD, Penakalapati G, Amato HK, Garn JV, Alexander K, Freeman MC, Boisson S, Medlicott KO, Clasen T. Assessing the impact of sanitation on indicators of fecal exposure along principal transmission pathways: a systematic review. Int J Hyg Environ Health. 2016;219(8):709-23.

19. Pickering AJ, Ercumen A, Arnold BF, Kwong LH, Parvez SM, Alam M, Sen D, Islam S, Kullmann C, Chase C. Fecal indicator bacteria along multiple environmental transmission pathways (water, hands, food, soil, flies) 
and subsequent child diarrhea in rural Bangladesh. Environ Sci Technol. 2018;52(14):7928-36.

20. WHO: Guidelines for drinking-water quality. Surveillance and control of community supplies. Volume 3; 2nd ed. Geneva. 1997. www.who.int/ water_sanitation_health/dwq/gdwqvol32ed.pdf. Accessed 04 July 2021.

21. Gwimbi P. The microbial quality of drinking water in Manonyane community: Maseru District (Lesotho). Afr Health Sci. 2011;11(3):477-80.

22. Hong Kong Food and Environmental Hygiene Department: Microbiological Guidelines for Food (For ready-to-eat food in general and specific food items). Centre for Food Safety. 2014. https://www.cfs.gov.hk/english/ food_leg/files/ready-to-eat-food.pdf. Accessed 27 July 2021.

23. WHO: Training manual on diagnosis of intestinal parasites based on the WHO bench aids for the diagnosis of intestinal parasites, district laboratory practice in tropical countries. WHO/CTD/SIP/98.2 CD-Rom. 2004. Available at http://usaf.phsource.us/PH/PDF/HELM/trainingmanual_ sip98-2.pdf. Accessed 27 May 2021.

24. Sanchez AL, Gabrie JA, Usuanlele M-T, Rueda MM, Canales M, Gyorkos TW. Soil-transmitted helminth infections and nutritional status in schoolage children from rural communities in Honduras. PLoS Negl Trop Dis. 2013;7(8):2378.

25. Chero JC, Saito M, Bustos JA, Blanco EM, Gonzalvez G, Garcia HH. Hymenolepis nana infection: symptoms and response to nitazoxanide in field conditions. Trans R Soc Trop Med Hyg. 2007;101 (2):203-5.

26. Sommet N, Morselli D. Keep calm and learn multilevel logistic modeling: a simplified three-step procedure using stata, R, Mplus, and SPSS. Int Rev Soc Psychol. 2017;30:203-18.

27. Mattioli MC, Boehm AB, Davis J, Harris AR, Mrisho M, Pickering AJ. Enteric pathogens in stored drinking water and on caregiver's hands in Tanzanian households with and without reported cases of child diarrhea. PLoS ONE. 2014;9(1):e84939.

28. Pickering AJ, Davis J, Walters SP, Horak HM, Keymer DP, Mushi D, Strickfaden R, Chynoweth JS, Liu J, Blum A. Hands, water, and health: fecal contamination in Tanzanian communities with improved, non-networked water supplies. Environ Sci Technol. 2010;44(9):3267-72.

29. Levy K, Nelson KL, Hubbard A, Eisenberg JN. Following the water: a controlled study of drinking water storage in northern coastal Ecuador. Environ Health Perspect. 2008;1 16(11):1533-40.

30. Rufener S, Mäusezahl D, Mosler H-J, Weingartner R. Quality of drinkingwater at source and point-of-consumption—drinking cup as a high potential recontamination risk: a field study in Bolivia. J Health Popul Nutr. 2010;28(1):34

31. Reed BC, Rasnake MS. An assessment of coliform bacteria in water sources near Appalachian Trail shelters within the Great Smoky Mountains National Park. Wilderness Environ Med. 2016;27(1):107-10.

32. World Meteorological Organization. Health and sanitation aspects of flood management. Integrated Flood Management Tools Series. 2015; 1:23. http://www.floodmanagement.info/publications/tools/Tools_23_ Health_and_Sanitation_Aspects_of_Flood_Management.pdf. Accessed 07 Aug 2021.

33. Mason MR, Encina C, Sreevatsan S, Muñoz-Zanzi C. Distribution and diversity of pathogenic Leptospira species in peri-domestic surface waters from south central Chile. PLoS Negl Trop Dis. 2016;10(8):e0004895.

34. Khatri N, Tyagi S. Influences of natural and anthropogenic factors on surface and groundwater quality in rural and urban areas. Front Life Sci. 2015;8(1):23-39.

35. Burkholder J, Libra B, Weyer P, Heathcote S, Kolpin D, Thorne PS, Wichman M. Impacts of waste from concentrated animal feeding operations on water quality. Environ Health Perspect. 2007;115(2):308-12.

36. Gizachew M, Admasie A, Wegi C, Assefa E. Bacteriological contamination of drinking water supply from protected water sources to point of use and water handling practices among beneficiary households of boloso sore woreda, wolaita zone, Ethiopia. Int J Microbiol. 2020;2020:1-10.

37. Sharma HR, Worku W, Hassen M, Tadesse Y, Zewdu M, Kibret D, Gashe A, Meseret M, Gessesse D, Kebede A. Water handling practices and level of contamination between source and point-of-use in Kolladiba Town, Ethiopia. Environ We Int J Sci Technol. 2013;8:25-35.

38. Agensi A, Tibyangye J, Tamale A, Agwu E, Amongi C. Contamination potentials of household water handling and storage practices in kirundo subcounty, kisoro district, Uganda. J Environ Public Health. 2019;2019:1-8.
39. Navab-Daneshmand T, Friedrich MN, Gächter M, Montealegre MC, Mlambo LS, Nhiwatiwa T, Mosler H-J, Julian TR. Escherichia coli contamination across multiple environmental compartments (soil, hands, drinking water, and handwashing water) in urban Harare: correlations and risk factors. Am J Trop Med Hyg. 2018;98(3):803.

40. Pickering AJ, Julian TR, Marks SJ, Mattioli MC, Boehm AB, Schwab KJ, Davis $J$. Fecal contamination and diarrheal pathogens on surfaces and in soils among Tanzanian households with and without improved sanitation. Environ Sci Technol. 2012;46(11):5736-43.

41. Ngure FM, Humphrey JH, Mbuya MN, Majo F, Mutasa K, Govha M, Mazarura E, Chasekwa B, Prendergast AJ, Curtis V. Formative research on hygiene behaviors and geophagy among infants and young children and implications of exposure to fecal bacteria. Am J Trop Med Hyg. 2013;89(4):709.

42. Ercumen A, Pickering AJ, Kwong LH, Arnold BF, Parvez SM, Alam M, Sen D, Islam S, Kullmann C, Chase C. Animal feces contribute to domestic fecal contamination: evidence from E. coli measured in water, hands, food, flies, and soil in Bangladesh. Environ Sci Technol. 2017;51(15):8725-34.

43. Lupindu AM, Dalsgaard A, Msoffe PL, Ngowi HA, Mtambo MM, Olsen JE. Transmission of antibiotic-resistant Escherichia coli between cattle, humans and the environment in peri-urban livestock keeping communities in Morogoro, Tanzania. Prev Vet Med. 2015;1 18(4):477-82.

44. Purohit MR, Chandran S, Shah H, Diwan V, Tamhankar AJ, Stålsby Lundborg C. Antibiotic resistance in an Indian rural community: a 'One-Health'observational study on commensal coliform from humans, animals, and water. Int J Environ Res Public Health. 2017;14(4):386.

45. Dos Santos S, Ouédraogo FdC, Soura AB. Water-related factors and childhood diarrhoea in African informal settlements. A cross-sectional study in Ouagadougou (Burkina Faso). J Water Health. 2015, 13(2):562-574.

46. Schriewer A, Odagiri M, Wuertz S, Misra PR, Panigrahi P, Clasen T, Jenkins MW. Human and animal fecal contamination of community water sources, stored drinking water and hands in rural India measured with validated microbial source tracking assays. Am J Trop Med Hyg. 2015;93(3):509.

47. Penakalapati G, Swarthout J, Delahoy MJ, McAliley L, Wodnik B, Levy K, Freeman MC. Exposure to animal feces and human health: a systematic review and proposed research priorities. Environ Sci Technol. 2017:51(20):11537-52.

48. Berendes DM, Yang PJ, Lai A, Hu D, Brown J. Estimation of global recoverable human and animal faecal biomass. Nat Sustain. 2018;1(11):679-85.

49. Daniels ME, Shrivastava A, Smith WA, Sahu P, Odagiri M, Misra PR, Panigrahi P, Suar M, Clasen T, Jenkins MW. Cryptosporidium and Giardia in humans, domestic animals, and village water sources in rural India. Am J Trop Med Hyg. 2015;93(3):596.

50. Feachem R, Mara D, Bradley D. Sanitation and disease [Internet]. Washington: Wiley; 1983.

51. Biswas S, Parvez M, Shafiquzzaman M, Nahar S, Rahman M. Isolation and characterization of Escherichia coli in ready-to-eat foods vended in Islamic University, Kushtia. J Bio Sci. 2010;18:99-103.

52. Islam M, Ahmed T, Faruque A, Rahman S, Das S, Ahmed D, Fattori V, Clarke $\mathrm{R}$, Endtz $\mathrm{H}$, Cravioto A. Microbiological quality of complementary foods and its association with diarrhoeal morbidity and nutritional status of Bangladeshi children. Eur J Clin Nutr. 2012;66(11):1242-6.

53. Doza S, Rahman MJ, Islam MA, Kwong LH, Unicomb L, Ercumen A, Pickering AJ, Parvez SM, Naser AM, Ashraf S. Prevalence and association of Escherichia coli and diarrheagenic Escherichia coli in stored foods for young children and flies caught in the same households in rural Bangladesh. Am J Trop Med Hyg. 2018;98(4):1031.

54. Parvez SM, Kwong L, Rahman MJ, Ercumen A, Pickering AJ, Ghosh PK, Rahman MZ, Das KK, Luby SP, Unicomb L. Escherichia coli contamination of child complementary foods and association with domestic hygiene in rural Bangladesh. Trop Med Int Health. 2017;22(5):547-57.

55. Food Standards Australia New Zealand (FSANZ). Compendium of Microbiological Criteria for Food (January 2018). ISBN: 978-0-642-34594-3. www.foodstandards.gov.au. Accessed 28 May 2021.

56. Mokhtari A, Jaykus L-A. Quantitative exposure model for the transmission of norovirus in retail food preparation. Int J Food Microbiol. 2009;133(1-2):38-47.

57. Bintsis T. Microbial pollution and food safety. AIMS Microbiol. 2018:4(3):377.

58. Bintsis T. Foodborne pathogens. AlMS Microbiol. 2017;3(3):529. 
59. Aiemjoy K, Gebresillasie S, Stoller NE, Shiferaw A, Tadesse Z, Chanyalew M, Aragie S, Callahan K, Keenan JD. Epidemiology of soil-transmitted helminth and intestinal protozoan infections in preschool-aged children in the Amhara region of Ethiopia. Am J Trop Med Hyg. 2017;96(4):866.

60. G/hiwot Y, Degarege A, Erko B. Prevalence of intestinal parasitic infections among children under five years of age with emphasis on Schistosoma mansoni in Wonji Shoa Sugar Estate, Ethiopia. PLoS ONE. 2014;9(10):e109793.

61. Shumbej T, Belay T, Mekonnen Z, Tefera T, Zemene E. Soil-transmitted helminths and associated factors among pre-school children in Butajira Town, South-Central Ethiopia: a community-based cross-sectional study. PLOS ONE. 2015;10(8):e0136342.

62. Mbae CK, Nokes DJ, Mulinge E, Nyambura J, Waruru A, Kariuki S. Intestinal parasitic infections in children presenting with diarrhoea in outpatient and inpatient settings in an informal settlement of Nairobi, Kenya. BMC Infect Dis. 2013;13(1):1-11.

63. Banerjee S, Ray S, Shrivastava P, Das DK. Prevalence of intestinal parasitosis among under-five children in a rural community of Purba Bardhaman District, West Bengal. Indian J Community Med. 2020;45(4):425.

64. Ferreira FS. Pereira FdLM, Martins MdRO: Intestinal parasitic infections in children under five in the Central Hospital of Nampula, Northern Mozambique. J Infect Dev Ctries. 2020;14(05):532-9.

65. Tinuade O, John O, Saheed O, Oyeku O, Fidelis N, Olabisi D. Parasitic etiology of childhood diarrhea. Indian J Pediatr. 2006;73(12):1081-4.

66. Gerba CP. Environmentally transmitted pathogens. In: Pepper IL, Gerba CP, Gentry TJ, Maier RM, editors. Environmental microbiology. Amsterdam: Elsevier; 2009. p. 445-84.

67. Fuhrmeister ER, Ercumen A, Pickering AJ, Jeanis KM, Crider Y, Ahmed M, Brown S, Alam M, Sen D, Islam S. Effect of sanitation improvements on pathogens and microbial source tracking markers in the rural Bangladeshi household environment. Environ Sci Technol. 2020;54(7):4316-26.

68. Steinbaum L, Mboya J, Mahoney R, Njenga SM, Null C, Pickering AJ. Effect of a sanitation intervention on soil-transmitted helminth prevalence and concentration in household soil: A cluster-randomized controlled trial and risk factor analysis. PLoS Negl Trop Dis. 2019;13(2):e0007180.

69. Goddard FG, Pickering AJ, Ercumen A, Brown J, Chang HH, Clasen T. Faecal contamination of the environment and child health: a systematic review and individual participant data meta-analysis. Lancet Planet Health. 2020;4(9):e405-15.

70. Bisanzio D, Mutuku F, Bustinduy AL, Mungai PL, Muchiri EM, King CH, Kitron U. Cross-sectional study of the burden of vector-borne and soiltransmitted polyparasitism in rural communities of Coast Province, Kenya. PLoS Negl Trop Dis. 2014;8(7):e2992.

71. Machado-Moreira B, Richards K, Brennan F, Abram F, Burgess CM. Microbial contamination of fresh produce: what, where, and how? Compr Rev Food Sci Food Saf. 2019;18(6):1727-50.

72. Krystosik A, Njoroge G, Odhiambo L, Forsyth JE, Mutuku F, LaBeaud AD. Solid wastes provide breeding sites, burrows, and food for biological disease vectors, and urban zoonotic reservoirs: a call to action for solutionsbased research. Front Public Health. 2020;7:405.

73. Parvez SM, Azad R, Pickering AJ, Kwong LH, Arnold BF, Rahman MJ, Rahman MZ, Alam M, Sen D, Islam S. Microbiological contamination of young children's hands in rural Bangladesh: Associations with child age and observed hand cleanliness as proxy. PLoS ONE. 2019;14(9):e0222355.

74. Fuhrmeister ER, Ercumen A, Grembi JA, Islam M, Pickering AJ, Nelson KL. Shared bacterial communities between soil, stored drinking water, and hands in rural Bangladeshi households. Water Res X. 2020;9:100056.

75. Wałaszek M, Kołpa M, Różańska A, Jagiencarz-Starzec B, Wolak Z, Wójkowska-Mach J. Nail microbial colonization following hand disinfection: a qualitative pilot study. J Hosp Infect. 2018;100(2):207-10.

76. Fagernes $M$, Lingaas $E$. Factors interfering with the microflora on hands: a regression analysis of samples from 465 healthcare workers. J Adv Nurs. 2011;67(2):297-307.

77. McGinley KJ, Larson E, Leyden J. Composition and density of microflora in the subungual space of the hand. J Clin Microbiol. 1988;26(5):950-3.

78. Hedderwick SA, McNeil SA, Lyons MJ, Kauffman CA. Pathogenic organisms associated with artificial fingernails worn by healthcare workers. Infect Control Hosp Epidemiol. 2000;21(8):505-9.

79. Bauza V, Ocharo R, Nguyen TH, Guest JS. Soil ingestion is associated with child diarrhea in an urban slum of Nairobi, Kenya. Am J Trop Med Hyg. 2017;96(3):569.
80. Ivoke N, Ikpor N, Ivoke O, Ekeh F, Ezenwaji N, Odo G, Iyaji F, Onoja U, Eyo J. Geophagy as risk behaviour for gastrointestinal nematode infections among pregnant women attending antenatal clinics in a humid tropical zone of Nigeria. Afr Health Sci. 2017;17(1):24-31.

81. Geissler PW, Mwaniki D, Thiong'o F, Friis H. Geophagy as a risk factor for geohelminth infections: a longitudinal study of Kenyan primary schoolchildren. Trans R Soc Trop Med Hyg. 1998;92(1):7-11.

82. Echazú A, Bonanno D, Juarez M, Cajal SP, Heredia V, Caropresi S, Cimino RO, Caro N, Vargas PA, Paredes G. Effect of poor access to water and sanitation as risk factors for soil-transmitted helminth infection: selectiveness by the infective route. PLoS Negl Trop Dis. 2015;9(9):e0004111.

83. Gizaw Z, Adane T, Azanaw J, Addisu A, Haile D. Childhood intestinal parasitic infection and sanitation predictors in rural Dembiya, northwest Ethiopia. Environ Health Prev Med. 2018;23(1):1-10.

\section{Publisher's Note}

Springer Nature remains neutral with regard to jurisdictional claims in published maps and institutional affiliations.
Ready to submit your research? Choose BMC and benefit from:

- fast, convenient online submission

- thorough peer review by experienced researchers in your field

- rapid publication on acceptance

- support for research data, including large and complex data types

- gold Open Access which fosters wider collaboration and increased citations

- maximum visibility for your research: over 100M website views per year

At BMC, research is always in progress.

Learn more biomedcentral.com/submissions 